\title{
Social Influence \\ In Computer-Mediated Communication: The Effects On Group Meeting Outcomes
}

Bouchaib Bahli, ESC Rennes School of Business, France

\begin{abstract}
Studies of managers and knowledge workers reveal that they spend a significant amount of their time in meetings, suggesting that meetings are an important part of one's working life. Findings in Group Support Systems research suggest that using computer-mediated communication enhances idea production in group meetings. Nevertheless, little attention has been given to how the communication medium, in electronic brainstorming, influences group meeting performance. Using a laboratory experiment, 259 subjects were randomly assigned to 51 groups. Three different treatment conditions were used: no public screen, public screen presented at the end of the meeting session, and public screen provided throughout. The results show that there is a significant performance difference between groups under the three treatment conditions. The findings of this study offer striking evidence that there are social group processes that may account for these performance differences including the self-evaluation potential, social loafing and performance matching effects. Implications of these findings for both researchers and practitioners are discussed.
\end{abstract}

Keywords: Group Support System; Group Performance; Social Group Processes

\section{INTRODUCTION}

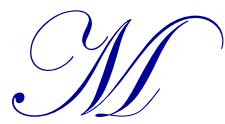

any reviews and surveys reveal that meetings dominate workers' and managers' time and yet are considered to be costly, unproductive and dissatisfying (Romano and Nunamaker, 2001). Studies of managers and knowledge workers reveal that they spend between $25 \%-80 \%$ of their time in meetings, suggesting that meetings are an important part of one's working life (Romano and Nunamaker, 2001). Furthermore, nowadays virtual groups are becoming a common component of both the corporate and educational structure (Pierzon, 2011; Piezon and Ferree, 2008) with social networks, corporations, educational institutions, and government agencies increasingly turning to virtual groups to bridge the difficulties associated with temporal and geographical separation (Forsyth, 2010; Bradner, 2003) and production blocking -the fact that only one member of a group can speak at a time during verbal brainstorming - (Tatcher and De La cour, 2003; Diehl \& Stroebe, 1991). One aspect of group work is brainstorming and probably the most important claim by Alex Osborn was the statement that brainstorming would allow the average person to come up with twice as many ideas when working with a group than when working alone (Forsyth, 2010. Ziegler et al. 2000).

With the advent of modern computer technology, one possibility to circumvent the problem of production blocking is the use of a computer network, which allows each group member to express his or her ideas at any time and nevertheless enables him or her to read other group members' ideas. Such a computer network has been used in a number of studies (DeSanctis et al. 2008. e.g. Gallupe et al. 1991; Valacich et al. 1992), most of which made use of a platform called group decision support systems (GDSS). Since their introduction in the 1980s, GDSSs have received considerable attention from practitioners and scholars alike in electronic brainstorming (EBS) (Rains, 2005). A GDSS is defined as an interactive computer-based system that combines communication, information, and decision support technologies in an integrated environment. Depending on their specific features, GDSSs can support face-to-face or distributed groups and single session or long-term groups (DeSanctis and Gallupe, 1987). At 
least three meta-analyses assessing the effects of GDSSs have been conducted involving more than 100 experiments (Dennis and Wixom, 2002; Postmes and Lea, 2000. Benbasat and Lim, 1993).

Despite a significant stream of GDSS research (DeSanctis et al. 2008) that attempted to identify the relative effectiveness of different features of these systems in different situations and to seek new and better configurations of this technology, little attention has been given to the role the communication medium, here the public screen, plays in an idea generation process and group performance (Fjermestad and Hiltz, 2001; Bahli, 1995; Valacich et al. 1994). The public screen is assumed to facilitate immediate display of group ideas communicated through the electronic channel and to enhance a group's attention to information it displays (Miranda 1994). Some GDSS studies suggested that group members, in an anonymous setting and using the public screen, participate extensively in generating ideas. Others found that the public screen might reduce the productivity loss that occurs during the idea-generation process (Fjermestad and Hiltz 2001). These inconclusive findings motivate this study to determine whether social group processes may explain group performance difference in GDSS setting, in the presence (or absence) of the public screen under an anonymous condition. The objective of the present study is to investigate the role and impact of the public screen manipulation on group performance in terms of unique ideas generated during an EBS session. To do so, we conducted a laboratory experiment in which three different experimental conditions were examined: no public screen; public screen presented at the end of the session; and public screen provided throughout.

This study's contributions are twofold. First, this study focuses on the role public screen manipulation has on group performance outcomes. Three conditions used in this study allow social group processes to emerge and, thus, provide an additional understanding of these processes and their effect on group meetings outcomes. Second, we believe that to focus entirely on only one social group process in groups is a truncated way to study group meetings. In EBS setting, public screen manipulation generates a contingent role of three social group processes all together, that is, social loafing, performance matching and self-evaluation potential. The rest of the paper is organized as follows. First, we provide the theoretical development of the study. Next, we describe the research method. Section three discusses the data analysis and results. We conclude the paper with a discussion of the study's implications for research and practice, its limitations and directions for further research.

\section{THEORETICAL DEVELOPMENT}

\subsection{The social loafing}

Social loafing is a general finding that when people perform in groups, they do less work or put in less effort than when working alone (Piezon and Ferre, 2008, North et al. 2000; Latané et al. 1979). It is a "hide in the crowd effect" where individuals may feel that because their individual contribution cannot be identified, it is unlikely that they will be singled out for credit or blame. Because individuals feel that their input is not essential to a high-quality group product, they expect their partners to loaf and, hence, loaf themselves rather than put out an inequitable amount of effort (Dommeyer, 2007). In addition, social loafing may occur when individuals are led to believe that the experimenter's interest is focused on group performance and that individual outputs are to be pooled. In other words, the experimenter is unable to evaluate their performance, their coparticipants cannot evaluate them, or they are unable to evaluate themselves (Jung et al. 2010. Szymanski and Harkins, 1987). However, determining the conditions under which individuals do or do not engage in social loafing can be problematic because the identification of means for devising interventions by which social loafing may be reduced or overcome in everyday groups and organizations and, hence, developing a fuller understanding of the dynamics underlying the performance and motivation of both individuals and groups (Alnuaimi et al. 2010. Aggarwal and O'Brian, 2008; Karau and Williams 1993, Weldon et al. 2000, Plaks and Higgins 2000).

In the present study, the manipulation of public screen usage in each of the three experimental conditions is intended to examine its impact on group performance in terms of unique ideas generated by the group. According to social loafing suggestions, we believe that groups without the public screen and under anonymity condition will have a tendency to reduce their own personal input since there is no incentive to exert an effort (Alnuaimi et al. 2010; Shih and Min, 2009; Connolly et al. 1990; Jessup and Tansik 1991; Connolly et al. 1993). 


\subsection{Performance matching}

The notion of performance matching is derived from the theory of social comparison or performance matching (Festinger, 1954). In social comparison processes pressure toward uniformity is present when opinions and abilities are evaluated. This pressure toward uniformity may result in performance matching. Performance matching due to social comparison has been proposed as one explanation for the observed productivity loss in group brainstorming (McLeod, 2000; Munkes and Diehl, 2003). Performance matching can occur in both directions: inferior group members tend to match the performance of superior group members and vice versa. In this model, people differ with regard to their tendency to match the performance of another person. If the tendency to match the performance of superior group members is stronger than the tendency to match the performance of inferior group members, a higher productivity will result (McLeod, 2000; Paulus \& Dzindolet, 1993).

When people are working toward a collective product, they often strive to deliver a performance that represents a fair contribution in relation to the total group performance (Van Leeuwen and Knippenberg 2002). In general, when people strive to deliver a fair share of effort, they try to match their performance to the performance expected from other group members- that is, they engage in performance matching (Karau and Williams 1993. When people expect low effort from other group members, performance matching may lead them to reduce their effort. As a consequence, the total group performance may be poor (Comer 1995). Hence, we believe that the presence of the public screen throughout the session will facilitate performance matching since group members will have the opportunity to see each other's effort level and match upward or downward their performance according to other group members' performance.

In this study, we assume that, while the use of the public screen may enhance the quality of feedback (Kwok et al. 2002), it may also lead to a more even influence distribution of effort (Huang et al. 1999). Through the public screen, individuals may discover that their performance is either similar to others, so, they tend to converge their effort to a similar (uniform) level of performance, or they may perceive their performance in a fairly positive way. Thus, while some participants once they have gained some notion of their competency on the task, they would have felt no need to maintain their performance, others are self-determined to outperform their peers.

\subsection{Self-evaluation Potential}

Attention has been directed toward self-evaluation potential as part of the renewed interest in the self (Jung and Schneider, 2010; Karakowsky and McBey 2001, Van Leeuwen and Knippenberg 2002). Although Latané et al. (1979) description implies that social loafing is simply a consequence of participants "working together", Harkins (1987) has suggested that this reduction in effort is a consequence of a particular feature of the experiments in which this effect has been found. Mainly, it was the lack of evaluation potential that led to social loafing. For evaluation to be possible, two pieces of information are necessary: some measure of output (e.g., the number of ideas a person generated) and some sort of standard against which this output can be compared (e.g., the number of ideas generated by others in the group). When group members are able to evaluate their performance they will be motivated to generate more ideas (Harkins and Jackson 1985, Karakowsky and McBey, 2001).

In the present study, we investigated the extent to which the presence or absence of the public screen in an electronic brainstorming session would have any effect on group performance, as measured by the individual mean of unique ideas generated by a group. Social loafing, performance matching and self-evaluation potential are examined by manipulating the public screen usage through three experimental conditions: 1) the public screen throughout the session where participants interact their ideas through the public screen without being able to identify other members ideas, 2) without the public screen throughout the session where participants had no chance to see other group members ideas, and 3) the public screen shown at the end of the session. Szymanski and Harkins (1987) have shown that the potential for self-evaluation in the context of idea generation can be manipulated simply by providing or withholding a standard typically based on participants' performance. In our study, participants with the public screen at the end (condition 3) are able to check how many ideas are generated by themselves as well as by their group members, which gives them a potential for self-evaluation. Groups without the public screen (condition 2) have no standard to evaluate their performance against individuals performing the same additive task in a group and, therefore, have tendencies to reduce effort and loaf during the whole session. Individuals may feel their inputs 
are not essential to a high-quality group product (Karau and Williams 1993). In addition, individuals may believe that the group product will be the sum of individuals' contributions so an individual is hidden in the group (Levine et al. 1993). Consequently, there is no incentive available for individuals to exert more effort.

Consequently, the above discussion suggests that there are three social group processes in play in the context of group meetings in an EBS session. Thus, we develop our hypotheses as follows:

Hypothesis I: Groups with the public screen at the end will generate more unique ideas than groups without the public screen because of self-evaluation effect.

Hypothesis 2: Groups with the public screen throughout will average their performance because of performance matching effect.

Hypothesis 3: Groups without the public screen will generate the lowest number of unique ideas because of social loafing effect.

\section{RESEARCH METHODOLOGY}

\subsection{Research Design}

To conduct this experiment, 259 undergraduate students participated in this laboratory experiment. 128 (49.4\%) men and $131(50.6 \%)$ women enrolled in an introductory management information systems course in a Canadian university. The mean age was 22 years. All participants have a working familiarity with microcomputers but none had previously participated in an electronic brainstorming study. Subjects were randomly assigned to 51 groups. The three conditions examined in this experiment are: 1) Condition 1 (public screen throughout): subjects had the possibility to view other members' comments on their individual screen. In addition, a group member under condition 1 could simply press the F8 key to see a set of ideas that had been generated by other group members; 2 ) condition 2: subjects generate ideas without being able to see other members' comments at all; 3) condition 3 : subjects were told at the beginning of the session that they will be seeing all group members' ideas at the end of the session. The F8 function was not activated during the session. The three conditions allowed a feasible test of the hypotheses. The experiment has 18 groups who performed with the public screen throughout, 16 groups with no public screen at all and 17 groups had the public screen at the end of the session.

Given the wealth of evidence from previous research that attest the importance of anonymity, we conducted our study in a full, strict anonymity in face-to-face setting. To ensure this anonymity, group members sat with paravents between them. No participant could see the computer monitor of any other person in the room. Anonymity was manipulated through a program that left user names unidentified. Group members could clearly see that their contributions during the idea generation process were not identified. The network system permits the display of information intended for the entire group on each individual's screen (public screen throughout, public screen at the end). Further, the group members interacted through the computer system only. Crosstalk (either verbal or nonverbal) was virtually non-existent. Each individual works alone and no interaction or possibility to see others' comments was possible.

\section{$3.2 \quad$ Task}

The idea generation task used in the present experiment was a standard, a relatively easy task that has been used in several previous studies (Karau and Williams1993). Participants were told that the more ideas they produce and the wilder the ideas, the better; and they should also improve and combine ideas already suggested (condition 1) and, most important, they should not be critical of the ideas of others and focus their ideas on an object uses only (the object is a knife). Osborn (1957) claimed that the adherence to these rules would more than double the ideas of individual group members. 


\subsection{Procedure}

The experiment was conducted in what DeSanctis and Gallupe (1987) refer to as a "Decision room" equipped with 10 'microcomputers, linked together through a local area network (LAN). The microcomputers are situated on a U-shaped table, with a chair for each microcomputer. The system is managed by a group facilitator who is stationed at the head of the room at a separate microcomputer and file server. The system used in this study is called GroupSystems V developed at the University of Arizona. We used the "Topic Commenter" feature because it allows more control on the public screen.

When subjects arrived at the GDSS lab, they were seated around a U-shaped table at individual microcomputers, each consisting of a colour monitor and keyboard. An experimenter then introduced himself or herself as well as each member of the group. He or she also mentioned to participants that they would perform in an anonymous setting. Depending on each experimental condition, the experimenter reads one of the three scripts. Script 1 (with the public screen through the session) reads, "During the whole session, you will be able to see all ideas displayed on this screen. However, none of you will be identified. Script 2 (Without the public screen) reads "There will be no public screen shown during this session, everyone will be able to display only his or her ideas on the private screen without being able to see other members ideas". Script 3 (with the public screen at the end) reads "you will be able to see the ideas of all members at the end of the session".

After the subjects had signed a consent form and an agreement of confidentiality, they completed a presession questionnaire that assessed their age, prior computer experience, self-reported knowledge speed, and attitudes toward working in groups and using computers. We collected the pre-session data as a check on the effectiveness of the random assignment to groups. The experimenter then explained the upcoming sequence of events and explained the rules for brainstorming as described by Osborn (1957). As a warm-up task, subjects had to brainstorm for $10 \mathrm{~min}$ on the topic "possibilities to reduce stress during the period of exams" After the brainstorming rules were reviewed, participants received the main topic "uses of knife". Groups had 20 min to generate ideas and a post-session questionnaire was then administered to assess members' perception of anonymity, degree of task difficulty. Participants were given the chance to evaluate some ideas through the vote option of GroupSystem V. The third and last questionnaire was designed to assess members' perception of satisfaction with the system. Finally, experimenters thanked subjects for their participation, and dismissed them.

\section{DATA ANALYSIS AND RESULTS}

Descriptive statistics show that participants believed that their outcome was anonymous $(\mathrm{M}=3.52$, S.D. $=$ $.61)$, that they found the task to be somewhat simple $(M=2.82$, S.D. $=.61)$, that they were satisfied with the EBS process $(M=3.53, S . D .=.29)$, rather satisfied with the quality of the ideas generated by their groups $(\mathrm{M}=2.84$, S.D. = .49), and satisfied with their individual performance during the EBS session $(\mathrm{M}=3.24$, S.D. $=.28)$. Descriptive statistics show also that subjects enjoyed using the GDSS $(\mathrm{M}=3.47$, S.D. $=.36)$, that they found it useful $(\mathrm{M}=3.44$, S.D. $=.35)$ and easy to use $(\mathrm{M}=4.52$, S.D. $=.38)$. Findings from a One-Way ANOVA test reveal some significant differences. Compared to the remaining groups, those without public screen found the task to be somewhat more difficult $(F=5.49$, Sig. $=.007)$ and the system to be less enjoyable $(F=6.86$, Sig. $=.002)$. Table 1 summarizes such findings.

Table 1. Statistics for process- and GDSS-related variables

\begin{tabular}{|l|c|l|}
\hline \multicolumn{1}{|c|}{ Variables } & Mean (SD) & \multicolumn{1}{|c|}{ Effect of the conditions } \\
\hline Anonymity of the process & $3.52(.61)$ & None $(\mathrm{F}=2.53$, Sig. $=.091)$ \\
\hline Satisfaction with the process & $3.53(.29)$ & None $(\mathrm{F}=.152$, Sig. $=.860)$ \\
\hline Task easiness & $2.82(.61)$ & $\begin{array}{l}\text { Groups without public screen found the task to be more } \\
\text { difficult }(\mathrm{F}=5.49, \text { Sig. }=.007)\end{array}$ \\
\hline Quality of ideas generated by the group & $2.84(.49)$ & None $(\mathrm{F}=.21$, Sig. $=.808)$ \\
\hline Satisfaction with individual performance & $3.24(.28)$ & None $(\mathrm{F}=3.08$, Sig. $=.056)$ \\
\hline Enjoyment with the GDSS & $3.47(.36)$ & $\begin{array}{l}\text { Groups without public screen found the GDSS usage less } \\
\text { enjoyable }(\mathrm{F}=6.86, \text { Sig. }=.002)\end{array}$ \\
\hline GDSS ease of use & $4.52(.38)$ & None $(\mathrm{F}=1.85$, Sig. $=.169)$ \\
\hline GDSS usefulness & $3.44(.35)$ & None (F = 2.36, Sig. =.178) \\
\hline All variables were measured on a five-point Likert scale $(1=$ Strongly disagree, $5=$ Strongly agree) \\
\hline
\end{tabular}

(C) 2013 The Clute Institute http://www.cluteinstitute.com/ 


\subsection{Scoring}

The number of non-redundant ideas for each group was assessed by two raters who performed this task separately and their judgment was based on the real and obvious uses as well as on the semantic meaning of the ideas (i.e. the verb open is chosen once even we may find several uses of it such as, open the door, open the window, etc.). The degree of agreement between the two coders was assessed using Diehl and Sroebe's formula (Diehl and Stroebe, 1991). The coefficient of concordance obtained was $98.45 \%$.

\subsection{Manipulations check}

The anonymity manipulation appears to have been successful. Participants believed that their outcome was anonymous $(\mathrm{M}=3.53$ on a scale of 5). Similarly, when we assessed the subjects' perception regarding the degree of task difficulty, we again found that all members qualified the task used as a simple task $(M=2.21)$. For the quality of ideas, the same pattern emerged, the subjects had assessed the quality of ideas generated by their group as a good ideas, $(M=2.18)$, and the ideas-generation process of their group was satisfying $(M=1.53)$. Also, participants viewed the ease of using the GDSS.

\subsection{The impact of the public screen on group performance}

The primary objective of this experiment is to test whether manipulating a public screen can improve the performance of participants to EBS sessions. Two series of statistical analyses were used to test our research hypotheses. First, a One-Way ANOVA was performed to examine the effects of the public screen on group performance as measured by the group's individual mean of unique ideas (Hypothesis 1 and 3). At the outset, the Levene test was used to assess whether the variances of the dependent variable were equal across the different groups. Where appropriate, a post hoc test (Scheffe or Games-Howell test, depending on the conclusions from the Levene test) was used as a follow-up test to compare means of three conditions. Second, F test for differences in two variances was performed to study the differences in variability in group's individual means of unique ideas (Hypothesis 2). A five percent level of significance was used for all the statistical tests.

The ANOVA test shows a significant difference in group's individual mean of unique ideas across the three groups of participants $(\mathrm{F}=24.83, \mathrm{Sig}=.000)$. Results from the Levene test confirm the heteroscedasticity of the dependent variable $($ Levene Statistic $=6.62$, Sig. $=.003$ ), and findings from the Games-Howell test show a significant difference between individual means of groups without the public screen $(\mathrm{M}=5.73)$ and those of groups with the public screen at the end $(M=6.40)$, and between means of groups with the public screen throughout $(M=$ 5.45) and those of groups with the public screen at the end. In contrast the difference between individual means of groups without the public screen and those of groups with the public screen throughout are not significant.

Findings from the one-tailed $\mathrm{F}$ tests for equality of two variances do not support the expected relationship between the public screen usage and the variability in individual means across the groups. For both comparisons, the $\mathrm{F}$ test statistic exceeds the lower boundary, indicating that the variance of the dependent variable is not lowest in the case of groups with the public screen throughout the session. The variance for the groups without public screen, with public screen at the end and with public screen throughout the session is $.11, .05$ and .28 respectively. When testing whether the variance of the individual means of unique ideas of groups with the public screen throughout is lower than those of groups without the public screen, the F-test statistic and the corresponding critical value on the F distribution are 6.47 and $.42(\mathrm{p}$-Value $=.999)$ respectively. When testing whether the variance of the individual means of unique ideas of groups with the public screen throughout is lower than those of groups without the public screen and lower than those of groups with the public screen at the end, the F-test statistic and the corresponding critical value on the $\mathrm{F}$ distribution are 31.36 and $.42(\mathrm{p}$-Value $=1)$ respectively. Table 2 summarizes findings from the ANOVA and the F tests for differences in two variances. 
Table 2. Tests results for the dependent variable

\begin{tabular}{|c|c|c|}
\hline Tests & Mean / S.D. & Conclusions \\
\hline One-Way ANOVA & $\begin{array}{l}\text { Groups of } 4: M=6.20 \\
\text { Groups of } 5: M=5.73 \\
\text { Groups of } 6: M=5.83\end{array}$ & $\begin{array}{l}\mathrm{F}=1.79 \text { (Sig. }=.178) \\
\text { No effect of group size of the groups' individual mean of non- } \\
\text { redundant ideas generated }\end{array}$ \\
\hline One-Way ANOVA & $\begin{array}{l}\text { Cond. } 1: M=5.45 \\
\text { Cond. } 2: M=5.73 \\
\text { Cond. } 3: M=6.40\end{array}$ & $\begin{array}{l}\mathrm{F}=24.83 \text { (Sig. }=.000) \\
\text { Post Hoc tests show that groups with public screen at the end } \\
\text { performed significantly better than the remaining groups but no } \\
\text { significant difference in performance between groups without public } \\
\text { screen and groups with public screen throughout }\end{array}$ \\
\hline $\begin{array}{l}\text { One-tailed } F \text { tests for } \\
\text { equality of variances }\end{array}$ & $\begin{array}{l}\text { Cond.1: S.D. }=.52 \\
\text { Cond.2: S.D. }=.33 \\
\text { Cond.3: S.D. }=.22\end{array}$ & $\begin{array}{l}\mathrm{F}=6.47 \text { ( } \mathrm{p}-\mathrm{Value}=.999) \text { : No significant difference in variance } \\
\text { between groups with public screen throughout and groups without } \\
\text { public screen } \\
\mathrm{F}=31.36(\mathrm{p}-\text { Value }=1) \text { : No significant difference in variance } \\
\text { between groups with public screen throughout and groups with } \\
\text { public screen at the end }\end{array}$ \\
\hline
\end{tabular}

\section{DISCUSSIONS AND CONCLUSIONS}

The research results yielded two insightful findings. First, as expected, our findings revealed that groups with the public screen at the end performed the best in terms of average number of unique ideas generated by each member of a group. The opportunity of self-evaluation may be sufficient to increase motivation and led subjects with the public screen at the end to exert more effort in generating ideas. Green (1989) alluded to the sufficiency of "internal standard" and evaluative potency of the private self to eliminate the loafing effect and motivate subjects performing better, even on the seemingly dull, uninteresting tasks (Karakowsky and McBey 2001). The potential for self-evaluation actually provided the subjects with two incentives (Szymanski and Harkins 1987, Van Leeuwen and Knippenberg 2002). They could learn something about their abilities on this task and they also could take pleasure in surpassing the performance of the "average" subjects. Thus, the subjects could have been motivated by the possibilities for self-evaluation (learning that they were better than average), and increasing self-knowledge (learning something about their abilities on the task) or by either of the two possibilities. This standard would be the participant's own earlier performances. Previous research (Szymanski \& Harkins 1987, Van Leeuwen and Knippenberg 2002) has shown that after participants have generated as many uses for an object as they can (brainstorming), they believe that they know how many uses they have generated. This suggests that the potential for self-evaluation on this task may be manipulated simply by providing or withholding a standard.

Another interesting finding regarding the variances within groups results indicate a significant difference between variance means of groups with the public screen throughout $(M=5.262)$ and both those of groups with the public screen at the end $(\mathrm{M}=11.702)$, and those of groups without the public screen $(\mathrm{M}=8.337)$. On one hand, as stated by Paulus \& Dzindolet (1993), this result may be explained by the fact that performance levels in electronic brainstorming groups are strongly affected by exposure to information about the performance of others or something about the interactive procedure itself is responsible for the productivity loss (Diehl and Stroebe 1993). Subjects may forget ideas while scanning others' ideas on the public screen, they may be distracted and wasted time for generating ideas or they may decide not to state ideas similar to those of others. On the other hand, we believe that comparison processes may motivate matching but also could be a source of frustration if one is not able to match the performance of one's partner. Because individuals in groups discover that their performance is fairly similar to that of others, they may perceive their performance in a fairly positive way, or they may tend toward uniformity in number of ideas generated (Paulus and Dzindolet 1993). Thus, participants were motivated by the potential for selfevaluation which elicit greater productivity even among subjects who believed that their individual inputs were anonymous (Shepperd 1993), but once they had gained some notion of their competency on the task, participants would have felt no need to maintain their performance (Harkins \& Williams 1985, North et al. 2000). Therefore, the performance matching effect adds an additional piece to the puzzle of how individuals behave generating ideas collectively through the public screen. We may conclude then that some subjects were not motivated to generate ideas, others exerted more effort to outperform their coactors even when they are not identified and not evaluated by the experimenter or by their partners. This matching phenomenon leads to equity in generating ideas, which is consistent with our expected results. 
These results have several important implications for both practice and research on how to effectively design EBS sessions in face-to-face and in virtual team settings and use the public screen in order to improve the idea-generation process. The nature of work in today's organizations has become more complex and global and team-based work has allowed those organizations to become more adaptive (Bell and Kozlowski 2002). In this context, designing effective teams becomes an imperative: if we aim to obtain more unique ideas, the results of our study suggest the use of the public screen at the end of the session. Also, not using a public screen should be avoided because it tends to make EBS sessions less enjoyable and more difficult and as a result may affect negatively the productivity of people working in teams. Hence, this study offers several indications about the public screen's manipulations and control and its impact on generating unique ideas. Researchers may well consider the compensating effects of this GDSS feature in their assessment of group performance.

This study has some limitations that must be mentioned. It is a laboratory rather than field experiment and we used unpaid student subjects. Further, the nature of the task the subjects performed (an easy task) may not be an involving, interesting task for students. In addition, the importance and influence of anonymity is likely to be less important in such setting. Groups of peers perceive anonymity to be less important than groups with hierarchical structure whose members had different power and status (Dennis, 1991). Because subjects were certainly aware of being in an experiment, using novel equipment, addressing problems of no special relevance to them, and over only a short time period, it is, perhaps, worth reiterating the usual cautions about over interpreting results from laboratory experiments using student subjects (Aiken et al. 1994). Despite these limitations, this study contribute to GDSS and social psychology research because it points out one of GDSS design features, that is the public screen, and the social group processes that play a contingent role in EBS setting on group meeting outcome.

Further research is needed to understand the full impact of the public screen on group performance, especially on an idea-generation process. First, future research might consider the design of the user interface and its relationship with anonymity. Ideas could be displayed on a screen in different windows (each participant has his 'or her window) without identifying or labelling the comments generated. Each group member may be able to evaluate and compare his or her performance (number of ideas displayed in his or her window) without losing anonymity. This feature could be used with the public screen throughout or at the end of a session in order to have a clear idea on the distribution of other members' performance without being able to identify them.

Also, it would be interesting to investigate the same pattern of our study, using different tasks, and/or other GDSSs with real groups in an organizational context. That is, to find out if the results hold over time. Also, it might be useful to simulate the idea-generation process. The facilitator supplies each individual a fictitious amount of ideas. For some a large number of ideas, for others a small quantity would be fed. This experiment would allow to control different GDSS variables such as loafing, self-evaluation, and to explore the ways individuals react in terms of performance to the amount of ideas generated.

\section{AUTHOR INFORMATION}

Bouchaib Bahli, ESC Rennes School of Business. 2 rue Robert d'Arbrissel- CS 76522. RENNES 35065. France. E-mail: bouchaib.bahli@esc-rennes.fr

\section{REFERENCES}

1. Alnuaimi, O; Robert, L; Maruping, L. (2010). Team Size, Dispersion, and Social Loafing in TechnologySupported Teams: A Perspective on the Theory of Moral Disengagement. Journal of Management Information Systems, 27(1) 203 - 230

2. Aggarwal, P., \& O’Brien, C. (2008). Social Loafing on Group Projects. Journal of Marketing Education, 30(3) 255-264.

3. Aiken, M., Martin, J., Paolillo, J. and Shirani, A.I. (1994). A group decision support system for multilingual groups. Information and Management, 26, 155-161.

4. Bahli, B. (1995). Productivity Loss in Performance Groups: The Role of GSS Interface. Unpublished graduate thesis, Laval University.

5. Bell, B.S. and Kozlowski, S.W. (2002). A Typology of Virtual Teams: Implications for Effective Leadership. Group \& Organization Management, 27, 14-49. 
6. Benbasat, I.,\&Lim, L. H. (1993). The effects of group, task, context, and technology variables on the usefulness of group support systems: A metaanalysis of experimental studies. Small Group Research, 24 , 430-462.

7. Bradner, E. (2003). Computer mediated communication among teams: What are "teams" and how are they "virtual"? In C. Lueg \& D. Fisher (Eds.), From usenet to cowebs: Interacting with social information spaces (pp. 135-154). London: Springer-Verlag.

8. Commer, R. (1995). A model of social loafing in real work groups. Human Relations, 48, 747-668.

9. Connolly, T., Jessup, L.M. and Valacich, J.S. (1990). Effects of anonymity and evaluation tone on idea generation in computer-mediated groups. Management Science, 36, 689-703.

10. Connolly, T., Routhieaux, R.L. and Schneider, S.K. (1993). On the effectiveness of group brainstorming: Test of one underlying cognitive mechanism. Small Group Research, 24, 490-503.

11. Dennis, A. R., \& Wixom, B. H. (2002). Investigating the moderators of the group support systems use with meta-analysis. Journal of Management Information Systems, 18, 235-257.

12. Dennis, A.R. (1991). Parallelism, anonymity, structure and group size in electronic meetings, Unpublished Ph.D Dissertation, University of Arizona.

13. DeSanctis, G., Poole, M. S., Zigurs, I., and Associates. 2008. "The Minnesota GDSS Research Project: Group Support Systems, Group Processes, and Outcomes," Journal of the Association of Information Systems, 9, 551-608.

14. DeSanctis, G.L. and Gallupe, R.B. (1987). A foundation for the study of group decision support systems. Management Science, 33, 589-609.

15. Diehl, M. and Stroebe, W. (1987). Productivity loss in brainstorming groups: Toward the solution of a riddle. Journal of Personality and Social Psychology, 53, 497-509.

16. Dommeyer, C. (2007). Using the Diary Method to Deal With Social Loafers on the Group Project: Its Effects on Peer Evaluations, Group Behavior, and Attitudes. Journal of Marketing Education, 29(2) 175188.

17. Dugosh, K. L., \& Paulus, P. B. (2005). Cognitive and social comparison processes in brainstorming. Journal of Experimental Social Psychology, 41, 313-320.

18. Festinger, L. (1954). A theory of social comparison processes. Human Relations, 7, 117-140.

19. Fjermestad, J. and Hiltz, S. (2001). Group support systems: a descriptive evaluation of case and field studies. Journal of Management Information Systems, 17, 115-159.

20. Forsyth, D. (2010). Group Dynamics (5th edition). Belmont, CA: Wadsworth/Cengage.

21. Gallupe, R. B., Bastianutti, L. M., \& Cooper,W. H. (1991). Unblocking brainstorms. Journal of Applied Psychology, 76, 137-142.

22. Green, R.G. (1989). Alternative conceptions of social facilitation, In P.Paulus (eds), The Psychology of Group Influence (New Jersey: Hillsdale), 15-51

23. Harkins, S.G. (1987). The Role of Evaluation in Eliminating Social Loafing. Journal of Experimental Social Psychology, 23, 1-18.

24. Harkins, S.G. and Jackson, J.M. (1985). The role of evaluation in eliminating social loafing. Personality and Social Psychology Bulletin, 11, 457-465.

25. Huang, W., Wei, K. and Tan, Y. (1999). Compensating effects of GSS on group performance. Information \& Management, 35, 195-202.

26. Jessup, L.M. and Tansik, D.A. (1991). Decision making in an automated environment: The effects of anonymity and proximity with a group decision support system. Decision Science, 22, 266-279.

27. Jung, J.H., Schneider, C., and Valacich, J.S. (2010). Enhancing the motivational affordance of information systems: The effects of real-time performance feedback and goal setting in group collaboration environments, Management Science, 56(4) 724-742.

28. Karakowsky, L. and McBey, K. (2001). Do my contributions matter? The influence of imputed expertise on member involvement and self-evaluation in the work group. Group and Organization Management, 26, 70-92.

29. Karau, J.S. and Williams, K. (1993). Social loafing: A Meta-Analytic Review and Theoretical Integration. Journal of Personality and Social Psychology, 65, 681-706.

30. Kwok, R., Ma, J. and Vogel, D. (2002). Effects of group support systems and content facilitation on knowledge acquisition. Journal of Management Information Systems, 19, 185-202. 
31. Latané, B., Williams, K. and Harkins, S. (1979). Many hands make light the work: The causes and consequences of social loafing. Journal of Personality and Social Psychology, 37, 823-832.

32. Levine, M.J., Resnick, B.L. and Higgins, T.E. (1993). Social foundations of cognition. New York: MacMillan.

33. McLeod, P. L., (2000). Anonymity and Consensus in Computer-Supported Group Decision-Making. In Research on Groups in Organizatios. T. I. Griffith (ed.), JAI Press, Stamford, CT.

34. Miranda, M.S. (1994). Avoidance of Group think: Meeting Management using Group Support Systems. Small Group Research, 25, 105-136.

35. Munkes, J., \& Diehl, M. (2003). Matching or competition? Performance comparison processes in an idea generation task. Group Processes \& Intergroup Relations, 6(3) 305-320.

36. North, A., Linley, A. Hargreaves, D. (2000). Social loafing in a co-operative classroom task. Educational Psychology, 20, 389-392.

37. Osborn, A.F. (1957). Applied imagination. New York: Charles Scribner's Sons.

38. Paulus, B. and Dzindolet, T. (1993). Social influence processes in group brainstorming. Journal of Personality and Social Psychology, 64, 575-589.

39. Piezon, S. (2011). Social loafing and free riding in online learning, ProQuest Dissertations and Theses. Retrieved from ProQuest Digital Dissertations (3477200). Retrieved from http://etd.lib.fsu.edu/theses/available/etd-04092011-134453/unrestricted/Piezon_S_Dissertation_2011.pdf

40. Piezon, S., \& Ferree, W. (2008). Perceptions of social loafing in online learning groups: A study of Public University and U.S. Naval War College students. The International Review of Research in Open and Distance Learning, 9(2). Retrieved from http://www.irrodl.org/index.php/irrodl/article/view/484/1034

41. Plaks, J. and Higgins, T. (2000). Pragmatic use of stereotyping in teamwork: social loafing and compensation as a function of inferred partner-situation fit. Journal of Personality and Social Psychology, 79, 962-974.

42. Postmes, T., \& Lea, M. (2000). Social processes and group decision making: Anonymity in group decision support systems, Ergonomics, 43, 1152-1274.

43. Rains, S. A. (2005). Leveling the organizational playing field-virtually: A meta-analysis of experimental research assessing the impact of group support system use on member influence behaviors. Communication Research, 32, 193-234.

44. Romano, N. C., \& Nunamaker, J. F. (2001). Meeting analysis: Findings from research and practice. In Proceedings of the Thirty-Fourth Hawaii International Conference on System Sciences. Retrieved June 17, 2012, from www.computer.org/proceedings/cps_dl.htm

45. Shepperd, J.A. 1993, Productivity loss in performance groups: A motivation analysis. Psychological Bulletin, 113, 67-81.

46. Shih-Wei, C, Min, H. (2009). The impact of media on collaborative learning in virtual settings: The perspective of social construction. Computers \& Education 52(2) 417-431.

47. Szymanski, K. and Harkins, S.G. (1987), Social loafing and self-evaluation with a social standard. Journal of Personality and Social Psychology, 53, 891-897.

48. Thatcher, A. and De la Cour, A. (2003). Small group decision-making in face-to-face and computermediated environments: the role of personality. Behaviour \& Information Technology, 22, 203-218.

49. Valacich, I.S., Dennis, A.R. and Connolly, T. (1994). Idea generation in Computer-Based Groups: A new ending to an old story. Organizational Behaviour and Human Decision Processes, 57, 448-467.

50. Valacich, J. S., Jessup, L. M., Dennis, A. R., \& Nunamaker, J. F. (1992). A conceptual framework of anonymity in group support systems. Group Decision and Negotiations, 1, 219-241.

51. Van Leeuwen, E. and Knippenberg, D. (2002). How a group goal may reduce performance matching in group performance: shifts in standards for determining a fair contribution of effort. The Journal of Social Psychology, 142, 73-86.

52. Weldon, S., Blair, C. and Huebsch, P. (2000). Group remembering: does social loafing underlie collaborative inhibition?. Journal of Experimental Psychology, 26, 1568-1577.

53. Ziegler, R., Diehl, M., \& Zijlstra, G. (2000). Idea production in nominal and virtual groups: Does computer-mediated communication improve group brainstorming?. Group Processes and Intergroup Relations, 3(2), 141-158. 